\title{
Game Analysis on Rural Land Transfer from the Perspective of Stakeholder Theory
}

\author{
Zhang Gen ${ }^{1, \mathrm{a}}$, Zhang Qiance ${ }^{2}$ \\ ${ }^{1}$ School of Philosophy and Politics, Yunnan University of Nationalities, 650031Kunming, China \\ ${ }^{2}$ School of Chemical Science and Technology, Yunnan University of Nationalities, 650031Kunming \\ Yunnan, China
}

\begin{abstract}
The key-to maintaining social stability in rural areas, promoting rural economic development and building a new socialist countryside - is handling correctly the issues of rural land transfer and ironing out the conflicts resulting from the benefits imbalance. In this paper, rural land transfer is categorized into two types: land transfer caused by the collective behavior and land transfer caused by the individual behavior. In the process of land transfer caused by the collective behavior, the conflicts root in the convergence of interest among various rural social strata; while in the process of land transfer caused by the individual behavior, the game between interests and human relationship, reflects the dilemma between rationality and sensibility, which villagers are confronted with.
\end{abstract}

Keywords. land; transfer; Stakeholder theory; game; expression of interest; circulation

\section{Introduction}

As an important means to protect the basic rights and living security of farmers, land plays an irreplaceable role in China's vast rural areas. Since the land issues are the core of the "Three Agriculture" issues, land transfer and the resulting disputes have become the focal point of agriculture-related problems. With the accelerating process of urbanization, land transfer is wildly emerging in China's rural society. However, due to the ambiguous rural land property rights, together with the imperfect land transfer system and irregular operations, the policy implementation of land transfers is less impressive. Thus, many issues occurring during the land transfer process affect the smooth progress of rural land and do harm to the harmony and stability of rural society. Therefore, to maintain social stability, promote rural economy as well as establish a new socialist countryside, it is extremely essential to solve problems occurring during the process of current rural land transfer, and to iron out the conflicts resulting from the benefits imbalance.

\section{Rural land transfer and interest expression of villagers}

\subsection{Rural land transfer}

${ }^{a}$ Corresponding author: zhanggen20002@sina.com

This is an Open Access article distributed under the terms of the Creative Commons Attribution License 2.0, which permits unrestricted use, distribution, and reproduction in any medium, provided the original work is properly cited. 
In China, land transfer, actually is the transfer of land use rights. Farmers who own both the land contract and management rights, transfer the rights to use their land to other farmers or economic organizations, but to retain the contract rights of land. Land transfer is the extension and development of the Household Responsibility System. Depending on diverse subjects and modes of the land outflows, rural land transfer is categorized into two types: land transfer caused by the collective behavior and land transfer caused by the individual behavior. The main forms are as follows:

- Land transfer caused by the collective behavior: it refers to the land transfer, during which the collective organization dominates the collective land (by re-lease or rejection) for subletting to others. In this type, conflicts among various rural social strata are of most frequency.

- Land transfer caused by the individual behavior: it is the main type of rural land transfer, in which the land is transferred by households themselves, under the principles of legitimacy, willingness and compensation. Generally the contractor is limited to their own family land.

During the transfer process of rural land use rights, a complex game relationship between the outflow land owners and the inflow land owners turns up. Based on the demand for expanding their own interests, people from various strata consist of diverse interest groups. Surrounding land transfer, interaction alternates with conflict between stakeholders of different interest groups constantly. This interaction and conflict take place in the intersection between traditional Chinese culture and modern civilization, demonstrating the game in diverse forms and content.

\subsection{Stakeholder Theory}

It is acknowledged in social genesis that, during the social development process, those groups (or individuals) who have an impact on social events are defined as the event's stakeholders; those groups (or individuals) are closely related to both insiders and external associates; the development trend of social events depends on the organizational power of stakeholders. By repeating competition between these two levels, stakeholders ultimately achieve an equilibrium point in the game. As can be seen, the development of social events is an influence process from stakeholder to stakeholder, which consists of three stages. Firstly, the distinction of stakeholders' interests expression forms social events; after that, the participation of stakeholders (the intensity of their interest expression) influences the development of social events, while the development of social events also affects the content and form of stakeholders' interest expression; then, under the principle of maximizing the interests of all, stakeholders take part and achieve a balanced state in the game.

In the process of rural land transfer, all of rural social strata have become stakeholders in the transfer events, which consists of complex stakeholder relationships:

\subsubsection{Relationship networks of stakeholders in land transfer caused by the collective behavior}

Table 1. Subject-object relationship in land transfer process

Subject $\rightarrow$ Object

All//Part of the collective $\rightarrow$ Land inflows 
Table 2. Power/benefits of stakeholders in land transfer process

\begin{tabular}{|c|c|c|}
\hline \multirow{2}{*}{ Power } & \multicolumn{2}{|c|}{ Benefits } \\
\cline { 2 - 3 } & Lower & Higher \\
\hline Less & Economic elites\& intellectuals & Ordinary labourers \\
\hline More & Country squires & Political elites \\
\hline
\end{tabular}

Table 3. Rights/performance of stakeholders in land transfer process

\begin{tabular}{|c|c|c|}
\hline \multirow{2}{*}{ Rights } & \multicolumn{2}{|c|}{ Behavior Predictability } \\
\cline { 2 - 3 } & Lower & Higher \\
\hline Less & Economic elites\& intellectuals & Ordinary labourers \\
\hline More & Country squires & Political elites \\
\hline
\end{tabular}

As can be seen, in the process of land transfer, the status and demands of various interest groups are not the same.

In order to maintain the vested interests and status, political elites would have been on the warpath; less power as ordinary laborers posses, for their concern about the future, their interest demands are the highest and they might take the most resolute action, if necessary; country squires, with relatively lower interest demands (mainly for the construction and development of hometown), will support the expression of the ordinary laborers' interests, concerning for the social justice and their sympathy for vulnerable groups; economic elites and intellectuals, with both the lower power and less benefits, may swing around for their own survival considerations in the process.

\subsubsection{Relationship networks of stakeholders in land transfer caused by the individual behavior}

Table 4. Subject-object relationship in land transfer process

\begin{tabular}{|c|}
\hline Subject $\rightarrow$ Object \\
\hline Farmers (individual) $\rightarrow$ Land inflows (acquaintances in the village, friends and \\
relatives outside the village)
\end{tabular}

Table 5. Impact of interests /relationship on behavior

\begin{tabular}{|c|c|c|}
\hline \multirow{2}{*}{ Interest } & \multicolumn{2}{|c|}{ Relationship } \\
\cline { 2 - 3 } & \multicolumn{2}{|c|}{ Close } \\
\hline More & Predictable action (transfer) & Unpredictable action \\
\hline Less & Predictable action (transfer) & Predictable action (withhold) \\
\hline
\end{tabular}


As can be seen, in the land transfer process, the individual farmers prefer the relationship favor as priority, rather than interests. Under the premise of relationship favor, rational choice of interests still plays a role.

\section{Game between different rural strata in the land transfer caused by the collective behavior}

In the land transfer process caused by the collective behavior, the conflicts root in the convergence of land and the cognitive benefits. The higher cognitive convergence is, the less conflicts may occur, and vice versa. The process of conflicting, stimulating and resolving, occurs synchronously with the process of land transfer. The interests game around the rural land between all strata, actually equals the process of re-differentiation and reorganization of rural land portfolio. Thus, intense conflicts are rather unfavorable for stakeholders (political elite and the general public groups). Irrational action will contribute nothing but aggravate social tensions and undermine social harmony.

Case 1 is as follows:

In a certain village of southwest China, foreign businessmen planned to lease 33 acres of arable land from Party secretary Lee to plant flowers. Therefore, Lee held an internal committee meeting, passing the land sublease contract, with the price of 135 yuan per acre, for a period of five years, paid annually. However, the contract was not delivered to the all-villagers meeting. After the harvest, the village committee made a land distribution autocratically (the actual distribution of land was less than what should be), while retaining 33 acres of irrigated arable land for leasing to merchants. Village committee kept the rental of the first year to repay the debt of hospitality, instead of distributing profits to the villagers, which caused strong dissatisfaction. About the distribution of rental, quarrels between villagers and village cadres burst out by the end of that year. Later, due to the subsidies of planting and reduction of agricultural taxes, villagers unanimously required to reclaim the land. As the negotiation failed and complaints were not responded, raging villagers pulled out the trees on the land. Finally, with the mediation from a retired veteran cadres, villagers picked up the legal weapons to recover the land distribution.

The decision of subleasing land was only reached by village cadres in the caucus, while the villagers did not negotiate, which did not meet the villagers' autonomy program, and was against the principles of legitimacy, willingness and compensation. Also, this action violated the principle that the interests of the collective land must be allocated to all of the villagers. First of all, villagers clashed with village cadres, spontaneously and sporadically, but not to struggling for land. Nevertheless, after the ineffectiveness of quarrel, petition and other legal, semi-legal means, contradictory intensified gradually.

Stakeholders had been in interaction and conflict in the whole process, and their forces were fluctuating constantly. Initially, village cadres ignored the dominant position of the villagers, while villagers were put in information asymmetry position. When villagers spontaneously made remonstrance, village cadres spread remarks in public places, intending to prevent the protests (and to collapse intellectuals and economic elites). At this time, villagers were in a weak position, whose demands were not paid attention to, beginning to organize violence. Event was not shelved until the retired veteran helped villagers appeal to the court, after which the issue was resolved and the villagers recovered their land.

As can be seen from the analysis, in order to obtain performance and profit (bribery, sometimes), the political elites often show great interest in the transfer of collective land. Although the general public may hold an opponent attitude towards land transfer caused by the collective behavior, but as businessmen, rural intellectuals and economic elites differ from the ordinary laborers. As for country squires, even with less interest demands, based on the sense of social justice and their sympathy for vulnerable groups, they will support the expression of the ordinary laborers and become the de facto leader of ordinary farmers. Since it will not cause much impact for rural intellectuals to transfer collective land, consequently, with lower correlativity of interest and weaker interest demand, although they might put into the ranks of the opposition to the land transfer for various reasons, most 
rural intellectuals will give up their positions under pressure. In the transfer process, ordinary laborers are basically the weak, lacking the necessary legal knowledge, the predictability of the potential benefits and channels for the expression of interest. Along with the imperfect rural social security system, land may be the last bulwark of survival for these ordinary farmers. Besides, owing to the fact that the resulting compensation is much lower than the actual planting incomes, ordinary laborers are the most reluctant to sublease collective land.

The most common phenomenon in the conflict is that, almost all of the general public take action (spontaneously and sporadically), to quarrel a way to negotiate with the political elite, struggling for their own interests. Thus, the contradiction between the political elite and the general public is particularly prominent. However, to maintain their vested interests and status, the political elites are going to expand interest alliance, and try to prevent the general public from forming a common union. That's why the economic elites and rural intellectuals draw their attention. As the economic elites and rural intellectuals are able to gain more information via multi-channel, realizing the fact that the land transfer will not jeopardize their own interests, they are reluctant to adopt aggressive behavior and usually compromise under pressure from the political elites. Remaining neutral, economic elites and rural intellectuals will hold roughly convergence attitude (at least no longer revolt), temporarily in equilibrium. As for country squires, however, based on the sense of social justice and their knowledge of policy of the law, as well as for the construction and development of hometown, they will refuse to flatter the political elites and support the expression of the ordinary laborers .

With the worry about future living standards and the disappointment of local economic elites and intellectuals, interest demands of ordinary laborers enhance, forcing them to adopt more drastic action. Political elites take advantage of the information asymmetry, infringing ordinary laborers' rights to know and to participate in, so as to suppress their behavior. But the ordinary laborers will not surrender their own interests easily. After losing the support from economic elites and intellectuals, they tend to stand together with country squires for organized resistance. In order to enhance the game weights, ordinary laborers start violent confrontation, which exacerbate the conflicts. Violent confrontation might be able to end the conflicts on the surface, however, it cannot fundamentally resolve the conflicts. Thus, ordinary laborers should acquire more legal knowledge (by consulting a lawyer or acquaintances) and then the conflicts have entered the judicial process.

As far as we can draw a conclusion, that various stakeholders (interest strata) conflict due to the land transfer, and these conflicts root in the convergence of interest (the diversity of interest demands) among various rural social strata. The opponent strata are ordinary laborers and political elites. The country squires play roles of supporters and leaders of the ordinary laborers, while the economic elites and the local intellectuals remain neutral usually. The occurrence of conflicts is the inevitable result game among various rural strata. The manifestation of conflict is quarrel, while the highest form is violence, and ultimately it achieves a balanced game under the mediation of government or judicial procedure.

\section{Game between relationship and interest in the land transfer caused by the individual behavior}

Mr. Fei Xiaotong believes, in China, "For people who rely on agriculture, settlement is normal while migration is not." He suggested that China was a typical rural society, which was characterized by an acquaintance social structure, closed and strongly conservative. So he said, "In the differential pattern, social relations are gradually introduced from person to person. It is an increase in personal relationships, and the social context is a network composed of personal contact." Namely, the interpersonal distance of rural community pattern (the intimacy of social circle), is divided according to psychological distance, instead of the interest demands. Thus, farmers pay much attention to social relationships and emphasize acquaintances. Nowadays, Chinese rural society lies on the transition blend of traditional culture and modern civilization, the acquaintances social structure is not extinct, while the modern social structure that emphasizes fame (which is gradually corroding the rural social acquaintances structure) is not yet fully formed in the countryside. Relationship rules, the skeleton 
supporting rural social structure, still exist, and is going to have an important influence on the rural community. In fact, people in the rural community is not simply navigated by economy, they are affected by the traditional concepts, social circles and other social factors. Through the analysis on the game between relationship and interest in the land transfer caused by the individual behavior, it is demonstrated that the individual land transfer behavior actually is a complex social interaction behavior. As can be seen from Table 5, tough choice between rationality and sensibility exists in this type of land transfer.

In rural areas, land is not only the living guarantee of farmers, but also a traditional concept with abundant connotation. In the process of rural land transfer, emotional imprint can be found everywhere. Many cases of land transfer caused by the individual behavior are not in full accordance with the law of rational choice, but depending on the sensibility of social network's (the distance of acquaintances relationship). Most of the circulation objects are relatives, friends and acquaintances, with a transfer price far below the market price (even for free). Most of the farmers are more willing to transfer land to their own relatives and neighbors. As for the transfer mode, the emphasis on human relationships does not change significantly, the level of concern on the interests between stakeholders is rather low, and the interest demands are not so prominent. It is obvious that the process of rural land transfer causing by individual behavior is combined with traditional content, and it is decide by farmers' perception on traditional culture, customs and social networks.

Data obtained by the author in the survey are as follows:

Table 6. Scope and contract forms in land transfer process (percentage / frequency)

\begin{tabular}{|c|c|c|c|c|c|}
\hline \multirow{2}{*}{ Contract Forms } & \multirow{2}{*}{$\begin{array}{c}\text { Village } \\
\text { acquaintances }\end{array}$} & \multicolumn{3}{|c|}{ Outside the village } & \multirow{2}{*}{ Total } \\
\cline { 3 - 5 } & & Relatives & Friends & Groups & \\
\hline Oral & $33.04 \% / 38$ & $33.91 \% / 39$ & $21.74 \% / 25$ & $0 / 0$ & $88.70 \% / 102$ \\
\hline Formal & $6.96 \% / 8$ & $0 / 0$ & $1.74 \% / 2$ & $2.61 \% / 3$ & $11.30 \% / 13$ \\
\hline Total & $40 \% / 46$ & $33.91 \% / 39$ & $23.48 \% / 27$ & $2.61 \% / 3$ & $100 \% / 115$ \\
\hline
\end{tabular}

Note: This data table contains four transfer forms.

As can be observed from table above : for the land transfer objects, 97.39\% occurred among acquaintances in the village and friends together with relatives outside the village .The phenomenon that acquaintances in village is more likely to transfer land than those outside the village, may be related to the distance and other costs of planting .The verbal contracts obtained $88.70 \%$ of contracts while the formal contracts accounted for $11.30 \%$, which indicated that the land transfer causing by individual behavior is built on the trust in the acquaintances social structures .Also, it can be found via analysis that degree of trust between relatives is higher than that between acquaintances in village and friends (in the form of a written contract between village acquaintances, friends and relatives accounted for $6.96 \%, 1.74 \%, 0$, respectively), indicating that acquaintances social structure is no longer impregnable under the impact of modern civilization. However, the fact cannot be ignored that some people have a deep attachment to the land, preferring to create land shortage rather than transfer their land.

To introduce land transfer to the large-scale market, the construction of law of advantage and the decline of law of relationships must be achieved, on the basis of existing relationships. To enhance the interest demands, and to improve the concerns on interests, the disembodiment between people's interpersonal behavior and the law of relationship has to be realized, namely the rational choice. But, the warmth of traditional rural interpersonal networks will disappear. The perceptual choice based on the acquaintances social structure, matchs the real scenes of rural social life well, corresponding with the rural ethics, and makes up the alienation of modern society caused by rational choice. 


\section{Proposals to relevant issues}

\subsection{Enact and amend laws and policies of land transfer, introduce appropriate implementing rules}

In order to adapt to the new situation of the current rural land issues, relevant laws, regulations and policies about land transfer should promptly be formulated and revised, and the government ought to introduce appropriate implementing rules to protect farmers' interests in land transfer, as soon as possible. More explicit legal provisions detailed should be formed, to protect farmers' land contract rights in the legal rural land transfer. Besides, the rights of disposition are independent private economic rights during the contract period, maintaining the legitimate interest of transfer subject, and standardizing transfer action of land use rights.

At the same time, the government should encourage the development of various farmers' unions, strengthening farmers' own legal standards and self-protection awareness, establishing a sound social security system in rural areas, reducing the reliance of farmers on land. Furthermore, government action should be strictly regulated, and the function transformation of local governments should be accelerated, while effective measures ought to be taken to limit local governments act against the interests of farmers' land. Besides, the "central - province - county" administrative system and the directly management system of "county-village" should be implemented as soon as possible, so as to reduce administrative barriers and administrative costs in land transfer.

\subsection{Improve dispute resolution system and strengthen the guide of rational expression of interest, to solve the collective land transfer dispute}

In the land transfer process, irrational expression of interests effuses in rural areas, which directly affects the harmony and stability of rural society, the fundamental interests and the development of democracy. Hence, it is essential to further explore and improve the procedures, methods and systems of local governments and judicial mediation in the process of land transfer, and to increase farmers' expression channels of interest. Also, strengthening the guide of rational expression of interest, and constantly improving the ability of judicial mediation is necessary to effectively solve the collective land transfer dispute

In the resolution of land transfer dispute, four immutable points are as follows:

- Properties and purposes of the collective land shall not be changed and the rights along with interests of farmers shall not be jeopardized.

- Land transfer in permitted in many circulation forms, under the principles of legitimacy, willingness and compensation.

- The subjects of land transfer are farmers instead of cadres.

- Land transfer mechanism relys on the market rather than the government, the government should perform the functions of service.

\section{References}

1. Baidu $\bullet$ baike $\bullet$ Land transfer entries [J/OL].http://baike.baidu.com/view/1258810.html? wtp=tt

2. H.Zhang,X.Li, and X.Shao. "Impacts of China's Rural Land Policy and Administration on Rural Economy and Grain Production". Review of Policy Research, vol.23 (2), pp607-624, March 2006.

3. Zhao Xudong., "Transcending Existing Traditions of Sociology-A Review of Fei Xiaotong's Reflections on Sociological Method in His Old Age*". Social Sciences in China. Beijing, vol.32, March 2011. 